\title{
SIGNIFICADOS E CONTEXTOS: LEITURA E INTERPRETAÇÃO NA CIÊNCIA DA INFORMAÇÃO
}

\author{
MEANINGS AND CONTEXTS \\ SIGNIFICADOS Y CONTEXTOS
}

Lourival Pinto ${ }^{1}$
${ }^{1}$ Universidade Federal de Pernambuco

Correspondência

${ }^{1}$ Lourival Pinto

Universidade Federal de Pernambuco

Recife, PE

E-mail: joaolori@yahoo.com.br

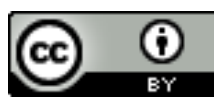

JITA: CF. Reading and story telling.

Submetido em: $14 / 05 / 2018$

Aceito em: 02/07/2018

Publicado em: 27/08/2018 
RESUMO: Este artigo tem como objetivo refletir sobre a relação entre as leituras, os significados, as interpretações e seus contextos, na ótica da Ciência da Informação. A pesquisa quanto aos objetivos, é exploratória, quanto aos procedimentos é bibliográfica, e traz como hipótese que as interpretações dependem diretamente do contexto espaço-tempo do leitor. O artigo traz uma revisão bibliográfica elegendo como temas principais de investigação os significados e seus contextos de significação. As considerações finais confirmam, mesmo que a priori, que as leituras são resultados de vivências dos leitores, sejam elas, resultantes de leituras textuais ou leituras de mundo. Além disso, o artigo defende que essas questões são fundamentais nos trabalhos de organização da informação e do conhecimento, e que as vivências podem acontecer nos processos de formação de leitores, facilitando a leitura das pessoas em estruturantes significantes mais complexas.

PALAVRAS-ChAVE: Leitor. Semiótica. Conhecimento e Informação.

ABSTRACT: This article aims to reflect on the relationship between readings, meanings, interpretations and their contexts, from the point of view of Information Science. The research on the objectives is exploratory, as far as the procedures are bibliographical, and hypothesizes that the interpretations depend directly on the space-time context of the reader. The article brings a bibliographical review choosing as main themes of investigation the meanings and their contexts of signification. The final considerations confirm, even if a priori, that the readings are the results of the readers' experiences, whether they result from textual readings or world readings. In addition, the article argues that these issues are fundamental in the work of organizing information and knowledge, and that the experiences can happen in the processes of formation of readers, facilitating the reading of people in more complex structures.

KEYWORDS: Reading. Semiology. Information and Communication.

RESUMEN: Este artículo tiene como objetivo reflexionar sobre la relación entre las lecturas, los significados, las interpretaciones y sus contextos, en la óptica de la Ciencia de la Información. La investigación en cuanto a los objetivos, es exploratoria, en cuanto a los procedimientos es bibliográfica, y trae como hipótesis que las interpretaciones dependen directamente del contexto espacio-tiempo del lector. El artículo trae una revisión bibliográfica eligiendo como temas principales de investigación los significados y sus contextos de significación. Las consideraciones finales confirman, aunque a priori, que las lecturas son resultados de vivencias de los lectores, sean ellas, resultantes de lecturas textuales o lecturas de mundo. Además, el artículo defiende que esas cuestiones son fundamentales en los trabajos de organización de la información y del conocimiento, y que las vivencias pueden ocurrir en los procesos de formación de lectores, facilitando la lectura de las personas en estructuras significantes más complejas.

PALABRAS CLAVE: Lectura. Semiología. Información y Comunicación. 


\section{INTRODUÇÃ̃o}

Este artigo apresenta como tema principal a relação entre as leituras, os significados, as interpretações e seus contextos, na ótica da Ciência da Informação. A questão de pesquisa se origina de nossa inquietação a respeito das múltiplas significações que as leituras podem provocar nos sujeitos receptores da leitura, e na retomada de uma construção textual com base nas leituras profundas empreendidas pelos mais diferentes leitores. Além disso, buscamos argumentar que a leitura é base da informação, e assim como tal, as questões de leitura envolvem diretamente os meandros técnicos da organização do conhecimento e da informação.

Com base nessas inquietações, chegamos a uma questão de pesquisa, a saber: por que leitores, na produção de sentidos, criam ou recriam diferentes significados para uma mesma estrutura significante? Essa estrutura pode ser um texto, um vídeo, um áudio, todos eles configurados num espectro amplo, daquilo que denominamos leitura. A hipótese é que essas interpretações dependem diretamente do contexto espaço-tempo do leitor. Sendo assim, com a finalidade de respondermos a essa pergunta, nosso objetivo principal de pesquisa é refletir sobre a relação entre os significados e seus contextos, especificamente nos atos de leitura e interpretação na Ciência da Informação.

A pesquisa, quanto à abordagem é qualitativa, quanto à natureza é aplicada, quanto aos objetivos, é exploratória, e quanto aos procedimentos é bibliográfica.

O artigo está dividido em seções, sendo que na segunda seção, refletimos sobre os significados de significado, na terceira seção apresentamos o contexto da significação, e finalmente, na quarta seção, apresentamos as considerações finais. Dito isto, na próxima seção, vamos discutir o significado de significado.

\section{OS SIGNIFICADOS}

No conceito semiótico, a significação se dá na relação entre significante e significado, sendo que o signo é "a correlação de uma forma significante com uma (ou com uma hierarquia de) unidade que definimos como significado" (Eco, 1997, p. 150).

$\mathrm{Na}$ relação entre significante e significado, o que se observa e se nomeia como um signo constitui apenas a forma significante. O significado é o conteúdo da expressão sígnica (significante).

Ogden \& Richards (1976) argumentam que as palavras nada significam por si mesmas, mas quando utilizadas elas representam alguma coisa ou, numa determinada acepção têm um significado. Para se comunicar, o sujeito utiliza os recursos sígnicos, que são referências a 
objetos que não estão presentes, ou que sejam abstratos, ou que estejam presentes, mas que tenham significados diferentes.

Ao postular um signo e seu significado, o sujeito se comunica por meio da fala ou da escrita ou mesmo de gestos, naquilo que Blumer (1969) chamou de interação simbólica. Para maior clareza, o recurso a um signo de uma unidade cultural traz em si elementos comuns de interação entre indivíduos comunicantes. Ao recorrer a esses signos, o indivíduo busca e alcança uma representação, na medida em que representa um referente por meio de um signo. Assim expressão-conteúdo caminham juntos no nível de unidades culturais distintas, e se separam, se alternam e se juntam novamente no ato de uma nova representação, ou nos significantes de 'novas' unidades culturais.

Eco (1984), ao citar o triângulo conceitual estabelecido por Ogden \& Richards (1976, p. 32) diz que nessa relação, a expressão de um signo se conecta com a intensão e com a extensão de uma expressão. Para Ogden \& Richards, as três pontas do triângulo são: símbolo, referência e referente. Eco, na crítica a esse modelo argumenta que ele dá margens a ambiguidades, porque quando se refere ao referente, não esclarece se é um objeto ou uma classe de objetos. Quando alguém cita um cavalo (símbolo), faz-se referência a um cavalo específico de uma raça, ou à classe totalizante dos cavalos? Ainda de acordo com Eco, a solução seria postular um triângulo da seguinte maneira: expressão-intensão-extensão.

Lara (2001) esclarece que intensão é o conjunto de características constituintes de um conceito e que extensão é a totalidade dos objetos aos quais corresponde um conceito. $\mathrm{O}$ processo de comunicação que é baseado na relação de signos é codificado e decodificado por meio de códigos comuns, gerando a transmissão de uma informação que circula num grupo e /ou em vários grupos sociais. Os códigos são convencionados, e às vezes, na leitura e interpretação de um texto, o leitor pode se equivocar na tentativa de descobrir a intenção do autor, mesmo porque esse autor viveu e produziu o texto em outro universo de espaço-tempo, onde e quando os códigos comuns eram outros.

A esse respeito, Thornley \& Gibb (2009), buscando definir diferenças conceituais entre o significado de significado em filosofia e em recuperação da informação, argumentam que a lacuna de contexto nos documentos, quando estes estão afastados do tempo e do espaço em que foram gerados, podem causar uma fraqueza em termos de comunicação, mas muitas vezes, é uma força em termos de informação, por permitir que esta informação possa ter resistido através dos tempos e em diferentes lugares.

Mas, mesmo essa resistência não pode evitar, ou até mesmo acaba favorecendo, a multiplicidade de sentidos que são produzidos durante a leitura de um texto originário em outros contextos. E, teoricamente, nem seria necessário que acontecesse um distanciamento espaço-tempo tão elástico. Às vezes, basta um pequeno desvio contextual para acontecer a diversidade na produção de sentidos, porque de acordo com Croatto (1985), quanto maior é a distância entre escrita e leitura, maiores são as perspectivas da leitura de um texto.

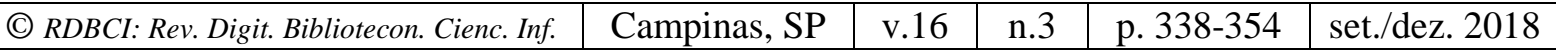


Portanto, essas variáveis (intenções, distâncias, vivências) influenciam a produção dos sentidos pelo indivíduo no momento da apreensão dos referentes. E é nesse momento que as unidades culturais se articulam para gerar um significante. Para compreender o significado de sentido e o significado num contexto de leitura, devemos identificar os fenômenos como eles se manifestam. Não é o caso de descobrir qual vem primeiro, o sentido ou o significado, mas talvez compreender que ao ler, o leitor produz um sentido significando, ou o signo significa com base num sentido. Husserl (1996, p. 33) afirma que:

as significações das respectivas proposições residem nos juízos sobre as vivências, e não nas próprias vivências, desejos, perguntas, etc. Da mesma maneira, as significações dos enunciados sobre as coisas exteriores também não residem nessas últimas (casas, cavalos, etc.), mas nos juízos que fazemos interiormente sobre elas ou nas representações que ajudam a construir esses juízos.

Nessa afirmação, o autor traz à tona a função do juízo e da representação no processo de significação, o que é corroborado por Tálamo (2004), quando diz que "atribuir um conceito a um termo depende da formulação de juízos". (p. 8). O juízo é, na realidade, um julgamento que vai dar qualidade a um termo, uma vez que é ele que vai determinar os objetos denotados, esclarecendo suas características individuais e gerais (enunciados de intensão e extensão).

Outra observação a ser feita a respeito da afirmação de Husserl é a noção de representação das coisas, ou seja, a utilização de um signo para significar algo que está encoberto. $\mathrm{O}$ objeto encoberto é representado por um signo para tornar viável a sua própria representação. A significação produz assim um processo de desdobramentos de símbolos, intensões e extensões, de acordo com as relações dos interpretantes.

Nas palavras de Heidegger (2004), a significação é a remissão da remissão de algo que se achava encoberto, mas vem ao encontro da presença, por meio de uma referência dentro de seu mundo, e se pronuncia através de um sinal de relação.

Os desdobramentos se articulam da mesma maneira quando alguém lê um texto, e se apropria dos significados do texto para produzir os sentidos de acordo como os significados se apresentam. E, fenomenologicamente, lê os conceitos como eles são apreendidos durante o processo de leitura, produção de sentidos, significação e conhecimento. Durante esse processo, o leitor é capaz de simultaneamente representar e interpretar o texto e transmitir a informação, de acordo com os conhecimentos prévios que antecedem a significação e podem estar acondicionados nos sentidos da alma, ou no sentido do seu próprio ser. Um objeto encoberto não necessariamente está escondido dos sentidos, mas, sim, que pode se mostrar de modo diverso daquele pretendido pelo autor (no caso da leitura), e sua leitura ser estabelecida conforme as vivências e conhecimentos prévios do leitor, fatores que podem determinar culturalmente a representação de um signo. 
Ao estabelecer um ato de leitura, o leitor recorre a esquemas que criam os sentidos para um texto. Fazem parte desse esquema o legado dos pré-conhecimentos que se instauram com as suas vivências e as suas memórias que daí emergem. Isso fica bem claro nas associações que o leitor formula com base nesses conhecimentos. Podemos mencionar o conceito de conhecimento colateral, estabelecido por Welb (Peirce, 1977), e que é chamado de conhecimento familiar por Widdowson (2007), e de conhecimento de fundo por Eco (1984).

Esses conhecimentos são necessários para a Pragmática, que leva em conta o mundo social do leitor, e o leva além do conhecimento puramente linguístico. É a Pragmática que supõe que o leitor já tenha os conhecimentos suficientes para compreender o que está escrito. São, na realidade, os esquemas produzidos na mente do leitor que vão subsidiá-lo no momento da leitura. E, ao se deparar com um novo signo, vai construindo suas hipóteses na tentativa de confirmá-las. É certo que podem acontecer de se confirmarem diferentemente das hipóteses estabelecidas previamente, dependendo do mundo em que se encontra o leitor, ou de como a sua consciência, ao se apoiar nas vivências, vai se apoiar em juízos para construir os significados.

Esse processo de produção dos sentidos para o leitor sedimenta a interpretação dos signos e conceitos apresentados no texto, e dá a ele condições de produzir seu próprio discurso. É nesse momento que surge a retórica, fenômeno de construção de conhecimentos baseado na informação recebida no (s) texto (s), porque é evidente constatar que a função do processo de significação é facilitar o processo de comunicação.

Ao receber a informação e processar o conhecimento, o indivíduo estabelece uma relação da informação recebida do ambiente externo com o conhecimento subjetivo. Percebese que sempre haverá um conhecimento subjetivo, e que ao longo da sua vida informacional, o indivíduo altera constantemente o seu estado de conhecimento. Dizemos isso de uma maneira sócio-cognitiva de se ver o processo de informação, porque a busca da informação sempre acontecerá num ambiente externo por meio de interações sociais. É bem provável que a partir das primeiras informações recebidas, já nos seus primeiros tempos de vida, o indivíduo comece a processar informação e sedimentar o conhecimento.

$\mathrm{Na}$ leitura de um texto, ao produzir sentidos, o leitor estabelece relações de estados de mundo com os símbolos (ou signos). Ao se deparar com uma dada expressão, ele recorre aos seus esquemas na busca por um sentido. Ao fazê-lo, busca o recurso imediato de um símbolo (ou signo) que dê conta de representar aquela expressão. É certo afirmar que o que o leitor faz é estabelecer juízos de comparação, e seguir significando de acordo com seus sentidos. Então ele recorre aos signos, que têm a função de representar o significado e proporcionar os sentidos num mapa conceitual.

No campo da Ciência da Informação há várias revisões de literatura que procuram traçar um painel da sua intersecção com outras áreas de conhecimento. Mendonça (2000) faz

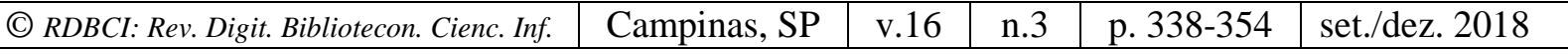


os estudos das conexões com a linguística. De acordo com ela, a Ciência da Informação mostra dependência em relação à linguística, porque em seu domínio de estudo, é imprescindível o uso da linguagem, que é o próprio objeto do conhecimento.

Para Mendonça, "é no ato de conhecer (conteúdo) e representar (linguagem) que a Ciência da Informação definirá o seu objeto de estudo - a informação -, e esta informação não pode ser formulada sem uma linguagem dependente, porém própria” (p. 65). Para representar o conteúdo de documentos, a Ciência da Informação se utiliza de recursos emprestados à Linguística, à Terminologia e à Semiótica. Num sistema de representação conceitual, um conteúdo é representado por termos com base em escolhas (paradigmas), e são feitas as combinações (sintagmas) desses termos para formular uma busca de informação.

Na linguagem comum, ao formularmos uma frase, fazemos determinadas escolhas de expressões em preterimento de outras. Assim, ao dizermos o semáforo ficou verde e os carros passaram, poderíamos ter dito o sinal ficou verde e os automóveis passaram. Nesse caso, escolhemos semáforo e não sinal, e preferimos carros e não automóveis. É um processo de escolha, ao mesmo tempo em que combinamos $o+$ semáforo + ficou + verde $+e+o s+$ carros + passaram.

Na Ciência da Informação, o processo é semelhante, ou seja, na análise conceitual de um documento ou de um domínio, são escolhidos os termos que melhor representem os conceitos. Podemos determinar que o termo carro representará melhor o conceito de um veículo de quatro rodas movido a motor e combustível, que possa ser conduzido por um motorista, do que o termo automóvel. E tal linguagem deve ser construída para facilitar que o usuário ao recorrer ao sistema possa combinar alguns termos para permitir sua busca. Tal combinação é feita com base em álgebra booleana, num processo de escolha, inclusão ou exclusão (or, and, not).

Semiologicamente, ao estabelecer os paradigmas e os sintagmas, o sistema de informação trabalha com significantes e significados, buscando uma correspondência com o usuário. Essa 'integração semiótica' deve trazer à tona os fenômenos de flutuação conceitual citados por Pinto em dissertação de mestrado (2005). Os significantes podem ter diferentes significados dependendo do tempo e do espaço em que estão, por exemplo, o autor e o leitor no momento da escrita e da leitura. O conceito de flutuação conceitual foi, por sua vez, tomado emprestado à Física para ser aplicado no sistema de significação.

Numa das teorias de Prigogine ${ }^{2}$ (Massoni, 2008) as coordenadas canônicas definem a posição (q) e o momento (p) dos pontos específicos das fases. Um fato, ou acontecimento

\footnotetext{
${ }^{2}$ Ilya Prigogine foi um físico-químico russo (1917-2003), ganhador do Prêmio Nobel de Química em 1977, por seus estudos em termodinâmica de processos irreversíveis com a formulação da teoria das estruturas dissipativas. Estruturas dissipativas são sistemas que retiram a energia do seu ambiente e produzem ordem. Prigogine conseguiu conciliar a teoria da evolução com a segunda lei da termodinâmica. (N. do A.)
} 
pode ocorrer em determinadas coordenadas, reduzindo a entropia e a ideia de irreversibilidade. Num sentido de caos, os fatos se dão em diferentes pontos, podendo ser revertidos, dependendo dos fenômenos que determinam as coordenadas, o que, em outras palavras, são as flutuações espaço-tempo. Esse, segundo Prigogine, é um dos princípios das incertezas que constituem os sistemas de mundos. É até pertinente reforçar que tal princípio se baseia na teoria da relatividade de Einstein, num sentido que os fenômenos se dão e são vistos dependendo do ponto onde estão e dependendo do ponto de onde e quando são observados.

Nas ligações da Ciência da Informação com alguns outros domínios, Saracevic (1995) mostra conexões com quatro áreas: Biblioteconomia, Computação, Ciência Cognitiva e Comunicação. Com a Biblioteconomia, as relações se dão principalmente nos processos de Recuperação da Informação em catálogos em linha. Com a Computação, a conexão se faz com computadores e redes. A preocupação das duas áreas são semelhantes em relação a armazenagem de dados, sistemas e técnicas para recuperá-los. A diferença é que a Computação se preocupa com a tecnologia mais eficiente que permitirá a viabilização desse processo, principalmente em grandes acervos físicos e em acervos digitais, enquanto a Ciência da Informação se atém mais ao conteúdo informacional e às linguagens eficientes para a Recuperação da Informação.

Com a Ciência Cognitiva, a ligação se apresenta nas teorias e experimentações da Inteligência Artificial e da Interação Homem-Máquina ${ }^{3}$, não vinculando as correspondências às tecnologias, mas às simulações do pensamento humano para viabilizar as possibilidades de adequar os processos das máquinas ao modo como o homem pensa, conceitua, analisa e sintetiza as informações. Sistemas de significação visam a um processo de comunicação, em que há o emissor, a codificação, a mensagem, a decodificação e o receptor. A informação permeia todo esse processo e pretende atingir seu objetivo, que é o de comunicar.

Algumas observações se fazem necessárias aqui: todo processo de interdisciplinaridade pressupõe trocas. A colaboração entre os domínios se dá em mão dupla. Basta verificar que se não há informação, não há sentido de se construir tecnologias de comunicação. E se não há tecnologia apropriada, os serviços de informação correm o risco de se tornarem de difícil acesso aos usuários. E, também, sem o uso das tecnologias, os próprios serviços serão feitos de maneira precária. E, quando se diz tecnologias de comunicação, já se prenuncia uma prática interdisciplinar, porque conecta comunicação e computação.

Outra observação a se fazer é que sempre surgem novas conexões entre os domínios. Um exemplo é no que se refere aos estudos da linguagem, que aponta colaborações entre a terminologia e a análise documentária.

\footnotetext{
${ }^{3}$ Essa relação pode ser notada nos projetos de sites colaborativos de informação, e em alguns projetos da web semântica, como o uso das tecnologias na representação descritiva nos ambientes informacionais digitais. (Castro \& Santos, 2009).
} 
Ainda falando na relação da Ciência da Informação com a Ciência Cognitiva, Lima (2003) traça uma revisão das contribuições entre essas duas ciências, e reforça que essa ligação se dá principalmente durante os processos de categorização, indexação, recuperação da informação e interação homem-máquina. No que tange a esses quatro elementos, observamos que a categorização envolve a classificação para organização do conhecimento. Classificar é conhecer e a classificação se dá por meio de processos cognitivos de conhecimentos de domínios, classes e pela capacidade de categorizar, hierarquizar e relacionar coisas, fatos e fenômenos.

Indexação é a compreensão do texto para a análise, identificação dos principais elementos, construção dos conceitos e a representação por meio de termos. De fato, a indexação é claramente um processo cognitivo. Assim também se dá com a Recuperação da Informação, que é um processo mental do usuário que se articula com o sistema para recuperar o assunto desejado. Esse processo envolve os esquemas mentais do usuário, que podem facilitar a busca da informação. Esses esquemas são os pré-conhecimentos do usuário e sua intuição ao utilizar os recursos tecnológicos e conceituais do sistema que dependem, em grande parte, de como foram construídas as linguagens que darão acesso aos conceitos que são representados pelos termos buscados pelo usuário em linguagem natural.

Para Tálamo (2001), entre a terminologia e a documentação acontece uma conexão, no sentido de que a documentação se apropria da terminologia para operar as unidades de significação dentro das linguagens documentárias e, no contexto onde se dá a transmissão da comunicação, com base nos sistemas de significação. É conveniente explicar que, apesar de não ser uma disciplina de documentação, a Ciência da Informação estuda o fenômeno da informação em si mesmo e os seus vários contextos, inclusive o da comunicação. Assim, ela, ao se preocupar com os estudos em documentação, abstrai a informação do contexto e tenta apreender os diversos meandros por onde ela perpassa.

A documentação se constitui num desses meandros, e o uso da terminologia na documentação traz à tona as linguagens especializadas em seus diferentes domínios, e ao fazer o recorte em um determinado domínio, processa os signos conceituais de acordo com os recursos de indução e dedução, recorrendo a questões teóricas e práticas da terminologia. De fato, ao analisar um domínio para fazer uma representação, o documentalista recorre à terminologia da área para recortar os conceitos e adequá-los aos possíveis termos que respondam àqueles conceitos.

Assim, ao analisar um texto daquela área, lendo-o documentariamente, ele sabe que as palavras-chave podem dar uma pista dos conceitos presentes ali, mas, também deve saber que precisa recorrer ao mapa conceitual que represente a área, com suas relações e associações, para poder situar os conceitos de acordo com os descritores possíveis, que já foram préestabelecidos para seus respectivos conceitos. E, também deve ter consciência de que essas relações e significações no mapa conceitual são passíveis de flutuações. 
Além do sentido de interdisciplinaridade, a Ciência da Informação, segundo Wersig (1993) pode ser considerada uma disciplina interconceitual. Constituída como uma ciência pós-moderna, ela foge às regras de uma noção formal de disciplina clássica, com seus conceitos, métodos e linguagens próprios. No que concerne ao objeto de estudo, Wersig acredita que a dificuldade dessa nova ciência seja estabelecer informação como objeto de estudo que pode ser rejeitada como tal, por não ser um termo exclusivo da Ciência da Informação e que perpassa por todos os domínios científicos.

Wersig cita outros termos que podem estar na mesma situação, como conhecimento, cultura, realidade, arte e tecnologia. Pelas suas características genéricas, tais conceitos não podem ser considerados objetos de estudo de nenhuma disciplina ou ciência. O que o autor propõe é o entrelaçamento ${ }^{4}$ de conceitos, numa espécie de rede onde conceitos significassem algo de acordo com suas características em torno de si, e perpassassem em torno de outras disciplinas. Percebemos que a interdisciplinaridade pode ter vários significados nos sistemas de significação que envolvem a Ciência da Informação. Primeiramente, nas contribuições entre vários domínios com o objetivo de comunicar a informação, e em segundo lugar, nos conceitos comuns que se entrelaçam numa rede de relações e ganham significação.

Poderíamos propor também que há textos e significados interdisciplinares. Um texto pode gerar conceitos que se entrelaçam e alcançam significação em vários domínios. Tal entrelaçamento pode se realizar no desdobramento das representações que são feitas durante a leitura do texto. Os conceitos analisados e representados ganham 'nova vida' e estabelecem uma nova dialética com outros domínios. De outra forma de pensar, os conceitos, após a leitura, representação e produção de significados 'carregam' a informação para outros campos.

\section{O CONTEXTO DA SIGNIFICAÇÃO}

O termo 'antes de mais nada' significa que o contexto em que é aplicado tal conceito refere-se ao momento do sujeito antes de qualquer conhecimento. O que significa que, baseando-se em fenômenos como o Enigma de Kaspar Hauser ${ }^{5}$, seria uma pré-história do sujeito, antes da apreensão e afirmação da sua linguagem e do seu pensamento. A partir do momento em que se inicia o período de interações, o sujeito começa a se articular e a produzir seus conceitos baseando-se nas interações consigo mesmo e com o seu ambiente.

O texto bíblico que narra a 'Torre de Babel' remete a esse momento pré-histórico da linguagem, metaforicamente falando. É um momento em que uma primeira língua foi

\footnotetext{
${ }^{4}$ Wersig (1993) propõe a idéia de um entrelaçamento de conceitos semelhante ao trabalho do pássaro-tecelão. Essa interconceitualidade seria a agregação e relação de conceitos que fundamentam a Ciência da Informação. Esses conceitos são, de alguma maneira, a contribuição de diversos domínios para fundamentar a Ciência da Informação. Tal técnica, então, poderia ser aplicada às interconceitualidades dos domínios considerados interdisciplinares.

${ }^{5}$ Filme alemão dirigido por Werner Herzog, lançado em 1974, e que traz reflexões acerca da relação entre vivências e linguagem.

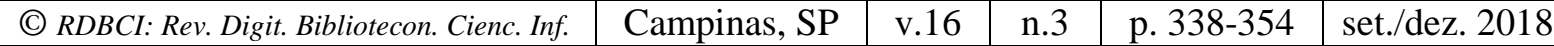


desfeita, para outras serem construídas. O fenômeno pode se apresentar como uma espécie de mito que explica a genealogia das línguas, e que tal genealogia foi construída ao longo dos séculos. Então, no momento em que o sujeito começa a se articular com o seu mundo, também se inicia seu processo de representação de mundo. Porque se os objetos ${ }^{6}$ do mundo ${ }^{7}$ não se apresentam de forma relacional, direta, ou se, pelo menos, em teoria, não é possível que isso aconteça, o sujeito recorre às representações dos objetos.

Na lógica heiddegeriana da fenomenologia, o sujeito (ente) interage com seu mundo antes de obter seus conhecimentos. Porque é através dessas interações e vivências, que os objetos do mundo se apresentam a ele, mas não apenas de uma maneira de ser como elas se apresentam de um modo definido. Não. O sujeito busca um sentido para as coisas ao investigar os objetos no seu sentido de ser. Em outras palavras, pergunta-se: porque esses objetos são? Qual o sentido desses entes que a ele se apresentam? É no momento da apreensão dos conceitos que eles são representados por signos (ou termos) que facilitam a comunicação entre os sujeitos do seu mundo.

Neste artigo, denominamos o ato de leitura como o do momento da apreensão, o do momento em que o sujeito/leitor apreende conceitos e os articula com sua perspectiva cognitiva. Não cabe aqui levantar questões como o estado cognitivo do sujeito no 'antes-demais-nada', mas apenas de propor uma linha de raciocínio comum entre esse momento e a explicação da interação do sujeito por meio de significados comuns a um mundo. Na préhistória do sujeito, conforme demonstrou Locke $e^{8}$, há os sentidos, mas sentidos num sentido (significado) de sensações. A partir das sensações, se estabelecem as vivências do sujeito no interior do seu mundo.

$\mathrm{O}$ ato de leitura, então, é um fator determinante para a produção de sentidos e significados e consequentemente para os fluxos de informação. Ao ler, o leitor evoca suas vivências, e traz à consciência os enunciados que dão vida aos conceitos, que por sua vez, darão sentidos aos significantes presentes no texto, baseados em comportamentos de julgamentos, ou nos juízos de comparação. Ao produzir os sentidos, são criados ou recriados os significados, que darão suporte a um possível diálogo com um sistema de informação.

Significar é interpretar, assim como classificar é conhecer. Isto significa que ao apreender o sentido do conceito e estabelecer significados, o leitor interpreta o texto de acordo com seus juízos e interações Também aqui cabe a questão: qual o objetivo de interpretar? Podemos criar hipóteses aqui, mas por ora, a resposta, que ainda não foi validada,

\footnotetext{
${ }^{6}$ Objetos aqui têm o significado de todas as coisas dentro do mundo. Tudo que existe, seja esse objeto tangível ou não. Em sentido restrito, poderia ser um ente (pessoa, coisa), algum referente, ou um fenômeno dado (N. do A.).

${ }^{7}$ Mundos no sentido das coisas comuns dentro de um universo dado. Esse mundo circunda o mundo conceitual do sujeito. Conceito de difícil apreensão, ainda mais que, relativamente, um mundo pode ser um objeto, porque ele também por si só é uma coisa intangível. Pode ser entendido também como um domínio do conhecimento, ou uma comunidade de pessoas. Seus significados comuns não são restritos, podendo ser compartilhados por outros 'mundos', por meio da transmissão de informações. (N. do A.).

${ }^{8}$ John Locke, filósofo inglês (1632-1704).

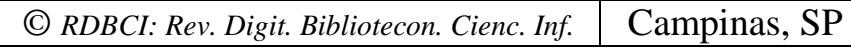

v.16

n.3

p. 338-354 1 set./dez. 2018
} 
é que a interpretação depende em parte do texto proposto e/ou da influência cultural que esse texto tem na comunidade. Definimos cultura, no atual contexto, como todos os fenômenos vistos como sociais, históricos, e temporais.

Devemos nos ater agora ao sentido de sentido e ao sentido de significado. Para Farradane (1979), o significado é o resultado da reação à informação interpretada associada às experiências do sujeito, e para Ogden \& Richards (1976), significado não tem um significado específico, mas múltiplos significados, dependendo da maneira como são contextualizados. Embora muito próximos em suas características, esses conceitos de sentido e significado são tratados aqui, na medida do possível, da seguinte maneira: o sentido é produzido pelo leitor, que ao ler, relaciona o texto com o seu universo.

Dentro do seu universo de compreensão, o leitor pode criar e recriar sentidos, dialogando com o texto e propondo ou não novas saídas. Os significados permeiam esse diálogo do início ao fim, normalizando as estruturas significantes, e nomeando os conceitos que surgem em decorrência dos novos sentidos atribuídos pelo leitor. Se, ao ler um texto, o leitor recria um novo universo à base de uma interpretação, os significados darão conta de estabelecer uma ligação dos termos desse universo com os conceitos atribuídos, criando ou recriando um mapa conceitual de expressões e conteúdos.

A explicação de Ferreira e Dias (2004) corrobora essa afirmação, quando dizem que sentido é tomado como algo pertencente ao universo pessoal do indivíduo, mas compartilhado dentro do contexto de interação, e significado é algo culturalmente compartilhado. Nessa afirmação, o conceito de significado fica muito conectado ao conceito de informação, uma vez que a informação é vista como um fenômeno que circula socialmente.

Tempos podem definir espaços, e vice-versa, e ambos afetam as vivências e as consciências. É necessário falar sobre as verdades, para esclarecer entendimentos acerca de significados verdadeiros ou não, até porque, em última análise, verdades absolutas não existem, e as afirmações de Eco (1995) e Ogden \& Richards (1976) corroboram isso, quando dizem que:

Assim sendo, quando você fala de verdade num mundo possível, penso que não esteja falando em termos de Verdadeiro 2, e sim em termos de Verdadeiro 1. Verdadeiro num mundo possível significa 'registrado numa enciclopédia'. Isso não tem nenhuma relação com a realidade. (Eco, 1995, p. 272, no diálogo do dr. Smith, Dpt. Of Cognitive Sciences, e Charles Sanders Personal, Computador Antipodiano)

A nossa interpretação de qualquer sinal é a nossa reação psicológica ao mesmo, tal como determinada pela nossa experiência passada em situações semelhantes e pela nossa experiência atual Se isso for enunciado com o devido cuidado, em termos de contextos causais ou grupos correlatos, obteremos uma explicação de julgamento, crença e interpretação que coloca a psicologia do pensamento no mesmo nível das outras ciências indutivas e, incidentalmente, liquida o 'Problema da Verdade' (Ogden \& Richards, 1976, p. 246-247). 
Devemos pensar a distinção de uma possível verdade na recepção da informação exclusivamente como responsabilidade e seleções dos sujeitos. Seria então o fenômeno apreendido e dado como uma verdade relativa por parte dos informantes e, possivelmente, como verdade em seus mundos que se correspondem. Searle (2002), relacionando significado e verdade contesta as argumentações de defesa do significado literal, ou seja, de que as sentenças se dão e são apreendidas num contexto zero ou contexto nulo. Segundo Searle a opinião dominante é de que as sentenças têm significado literal. "O significado literal de uma sentença é totalmente determinado pelos significados de suas palavras componentes e pelas regras sintáticas segundo as quais esses elementos se compõem" (p. 184). Corroborando Widdowson (2007) na questão linguística, e Lévy (1996) com relação à retórica, Searle se posiciona contra o significado literal e o contexto zero.

As expressões ou atos de fala se dão num contexto que define as verdades possíveis. Além da sintaxe e da gramática, a semântica (significado) e a pragmática (o uso da linguagem, como em Wittgenstein), determinam as significações em determinados contextos. Numa expressão simples como 'a neve é branca', que aparentemente possui um significado literal, existem questões subjacentes que determinam ou podem determinar seus significados. Em primeiro lugar, o contexto zero ou nulo nesse caso não existe. Talvez a compreensão dessa expressão seja diferente entre os povos esquimós e os beduínos do Saara, que nunca viram neve.

Para quem nunca viu neve, nem conhece suas características, a expressão pode se tornar sem sentido, daí o efeito da não-compreensão. Em segundo lugar, ocorre em qualquer sentença o fenômeno do conhecimento de fundo ou efeito colateral. Essa última observação é relacionada com os beduínos do Saara, pois o efeito colateral ou conhecimento de fundo exige que eles conheçam, previamente, o conceito de neve e saibam distinguir numa tabela de cores, a cor branca, ou mais especificamente, a cor branca semelhante à tonalidade da cor branca da neve.

Certamente que a inexistência de um contexto nulo ou de um significado literal nas expressões ou atos de fala (Searle, 2002), pode rejeitar o conceito de verdade absoluta, uma vez que o indivíduo que não consegue produzir sentidos para neve ou para a cor branca, pode invalidar como verdade a afirmação expressa na sentença 'a neve é branca'. Em contrapartida, pode propor outros 'jogos de sentidos' que tornam interpretações em verdades relativas ou possíveis.

\section{FINAIS}

Após as reflexões aqui feitas, concluímos, pelo menos por ora, que leituras são resultados de vivências, sejam elas, resultantes de leituras textuais ou leituras de mundo. A revisão bibliográfica, que foi o método aqui adotado, mostrou que a interpretação da leitura decorre de vivências dos sujeitos leitores. Para a interpretação, é necessária a compreensão,

\begin{tabular}{l|l|l}
$\mathrm{v} .16$ & $\mathrm{n} .3$ \\
\hline
\end{tabular}

\begin{tabular}{l|l} 
p. $338-354$ & set./dez. 2018
\end{tabular} 
que ocorre na dependência de conhecimentos prévios dos leitores. Tais conhecimentos podem ser de ordem social e/ou cognitiva, e influenciam claramente a significação dos mundos possíveis que se abrem aos leitores. Além disso, essas reflexões podem ser favoráveis a uma melhor compreensão dos processos de organização do conhecimento e da informação, visto que suas práticas envolvem leituras, tanto na entrada quanto na saída dos sistemas de informação, porque entendemos que leituras de mundos, de textos, ou as leituras especializadas, como as documentárias, estão sujeitas a esses fatores vivenciais.

As leituras são práticas sociais e trazem consigo complexidades que podem ser mais compreendidas por quem entende que o processo de produção e uso da informação é diretamente afetado pelas relações entre vivências, significados e produções de sentido. Sendo assim, consideramos que os resultados dessas reflexões liquidam com a falácia do tecnicismo na Ciência da Informação, uma vez que os processos de organização envolvem leituras e conhecimentos, e por isso são atividades humanas.

Nestas considerações finais, achamos pertinente destacar, ainda como fruto dessas reflexões, que a pesquisa nos trouxe perspectivas futuras de investigação na área de formação de leitores, tão pensada hoje na Ciência da Informação, e mais especificamente na Biblioteconomia. A leitura é uma atividade que deve ser desenvolvida, e assim como todo processo de desenvolvimento, ela exige um aumento da complexidade da leitura. A mediação de leitura pode elaborar seus projetos com o objetivo de relacionar as vivências das pessoas com suas possíveis leituras, e então empreender uma travessia em busca da compreensão de leituras mais complexas. Assim, entendemos que o próprio processo de mediação inclui-se nas memórias e vivências dos leitores, propiciando seu aprofundamento literário, e desenvolvendo nesses leitores o espírito sensível e crítico.

As leituras e suas possíveis significações influenciam diretamente na in/formação, que é o conjunto de atividades de informação e formação no universo que compreende as variáveis humanas e sociais das pessoas que produzem e usam informação.

\section{REFERÊNCIAS}

BLUMER, Herbert. Symbolic Interactionism: perspective and method. Berkeley and Los Angeles: University of California Press, 1969.

CASTRO, Fabiano Ferreira de; SANTOS, Plácida Leopoldina Ventura Amorim da Costa. Uso das tecnologias na representação descritiva: o padrão de descrição bibliográfica semântica MarcOnt Initiative nos ambientes informacionais digitais. Ciência da Informação, v. 38, n. 1, p. 74-85, jan./abr. 2009.

CROATTO, Joaquim Severino. Hermenêutica Bíblica: para uma teoria da leitura como produção de significado. São Leopoldo, RS: Sinodal; São Paulo: Paulinas, 1985.

ECO, Umberto. O conceito de texto. São Paulo: Queiroz, EDUSP, 1984.

\begin{tabular}{|c|c|c|c|c|c|}
\hline (C) RDBCI: Rev. Digit. Bibliotecon. Cienc. Inf. & Campinas, SP & v.16 & n. 3 & p. 338-354 & set./dez. 2018 \\
\hline
\end{tabular}


ECO, Umberto. O signo. 5. ed. Lisboa: Editorial Presença, 1997.

ECO, Umberto. Os limites da interpretação. São Paulo: Perspectiva, 1995.

FARRADANE, Jason. The nature of information: definitions and concepts of information. Journal of Information Science, v. 1, n.1, p. 13-17, abr. 1979.

FERREIRA, Sandra Patrícia Ataíde; DIAS, Maria da Graça Bompastor Borges. A leitura, a produção de sentidos e o processo inferencial. Psicologia em Estudo, v. 9, n. 3, p. 439-448, set./dez. 2004.

HEIDEGGER, Martin. Ser e Tempo, parte 1. 13. ed. Petrópolis, 2004.

HUSSERL, Edmund. Investigações lógicas, sexta investigação: elementos de uma elucidação fenomenológica do conhecimento. São Paulo: Nova Cultural, 1996 (Os Pensadores).

LARA, Marilda Lopez Ginez de. O unicórnio (o rinoceronte, o ornitorrinco...), a Análise Documentária e a Linguagem Documentária. DataGramaZero - Revista de Ciência da Informação, v. 2, n. 6, dez. 2001.

LÉVY, Pierre. O que é o virtual? São Paulo: ed. 34, 1996.

LIMA, Gercina Ângela Borém. Interfaces entre a ciência da informação e a ciência cognitiva. Ciência da Informação, v. 32, n. 1, p. 77-87, jan./abr. 2003.

MASSONI, Neusa Teresinha. Ilya Prigogine: uma contribuição à filosofia da ciência. Revista Brasileira de Ensino de Física, v. 30, n. 2, São Paulo, 2008.

MENDONÇA, Ercília Severina. A linguística e a ciência da informação: estudos de uma intersecção. Ciência da Informação, v. 29, n. 3, p. 50-70, set./dez. 2000.

O ENIGMA de Kaspar Hauser. Direção: Werner Herzog. Produção: Werner Herzog. Intérpretes: Helmut Doring; Bruno S.; Walter Ladengast; Brigitte Mira e outros. Roteiro: Werner Herzog, 1974. (110 min.), son., color.

OGDEN, Charles Kay; RICHARDS, Ivor Armstrong. O significado de significado: um estudo da influência da linguagem sobre o pensamento e sobre a ciência do simbolismo. São Paulo: Zahar, 1976.

PEIRCE, Charles Sanders. O que é significado?, de Lady Welb. In: PEIRCE, Charles Sanders. Semiótica. São Paulo: Perspectiva, 1977. p. 157-164.

PINTO, Lourival Pereira. A representação documentária e o paradigma social. 2005. 108 f. Dissertação (Mestrado em Ciência da Informação) - Escola de Comunicações e Artes, Universidade de São Paulo, São Paulo, 2005. 
SARACEVIC, Tefko. Interdisciplinary nature of information science. Ciência da Informação. Brasília, v. 24, n. 1, p. 36-41, 1995.

SEARLE, John. Expressão e Significado: estudos da teoria dos atos da fala. São Paulo: Martins Fontes, 2002.

TÁLAMO, Maria de Fátima Gonçalves Moreira. A pesquisa: recepção da informação e produção do conhecimento. DataGramaZero - Revista de Ciência da Informação, v. 5, n. 2, abr. 2004.

TÁlAMO, Maria de Fátima Gonçalves Moreira. Terminologia e Documentação. TradTerm, n. 7, p. 141-151, 2001.

THORNLEY, Clare; GIBB, Forbes. Meaning in philosophy and meaning in information retrieval (IR). Journal of Documentation, v. 65, n. 1, p. 133-150, 2009.

WERSIG, Gernot. Information Science: the study of postmodern knowledge usage. Information Processing \& Management, v. 29, n. 2, p. 229-239, 1993.

WIDDOWSON, Henry George. Discourse Analysis. Oxford, UK: Oxford University Press, 2007.

WITTGENSTEIN, Ludwig. Investigações filosóficas. 5. ed. Bragança Paulista, SP: Ed. Universitária São Francisco; Petrópolis: Vozes 2008. 


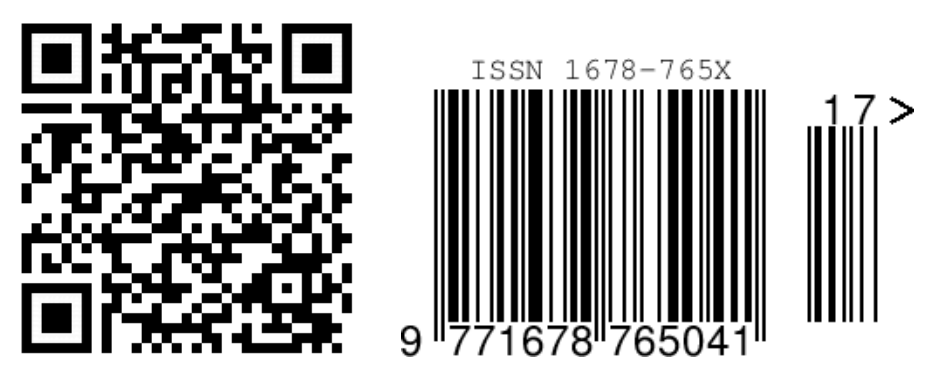

